Int. Agrophys., 2014, 28, 549

www.international-agrophysics.org

doi: 10.2478/intag-2014-0046

ERRATUM Int. Agrophys., 2014, 28, 73-83 doi: $10.2478 /$ intag-2013-0029

\title{
Erratum to: Modelling and analysis of compressive strength properties of parboiled paddy and milled rice
}

\author{
Abozar Nasirahmadi ${ }^{1 *}$, Mohammad H. Abbaspour-Fard ${ }^{1}$, Bagher Emadi ${ }^{1}$, and Nasser Behroozi Khazaei ${ }^{2}$ \\ 'Department of Agricultural Machinery, Ferdowsi University of Mashhad, P.O. Box. 91775-1163 Mashhad, Iran \\ ${ }^{2}$ Department of Agricultural Machinery, Kurdistan University, Sanandaj, Iran
}

Received March 17, 2013; accepted August 6, 2013

\section{Corrected author affiliation}

Abozar Nasirahmadi ${ }^{*}$, Mohammad H. Abbaspour-Fard ${ }^{1}$, Bagher Emadi ${ }^{1}$, and Nasser Behroozi Khazaei ${ }^{2}$

'Department of Agricultural Machinery, Ferdowsi University of Mashhad, P.O. Box. 91775-1163 Mashhad, Iran

${ }^{2}$ Department of Agricultural Machinery, University of Kurdistan, Sanandaj, Iran 